\title{
PELATIHAN PERMAINAN TRADISIONAL WUJUD PELESTARIAN PERMAINAN BERBASIS LOCAL GENIUS DI LINGKUNGAN SEKOLAH DASAR
}

\author{
Putu Beny Pradnyana1), I Nyoman Sudirman²), Pande Agus Adiwijaya3), \\ Desak Putu Anom Janawati ${ }^{1)}$
}

\begin{abstract}
1)Program Studi Pendidikan Guru Sekolah Dasar, Institut Teknologi dan Pendidikan Markandeya, Bali, Indonesia
2)Program Studi Bahasa dan Sastra Indonesia, Institut Teknologi dan Pendidikan Markandeya, Bali, Indonesia

3)Program Studi Pendidikan Bahasa Inggris, Institut Teknologi dan Pendidikan Markandeya, Bali, Indonesia
\end{abstract}

Corresponding author: Putu Beny Pradnyana

E-mail : putubenypradnyana380@gmail.com

Diterima 30 Juli 2021, Direvisi 02 Agustus 2021, Disetujui 02 Agustus 2021

\begin{abstract}
ABSTRAK
Tujuan pengabdian masyarakat ini adalah membantu Sekolah Dasar Negeri 3 Pengotan untuk memberikan pelatihan ekstrakurikuler permainan tradisional dalam rangka mengenalkan permainan tradisional yang ada di daerah Bali. Pengabdian kepada masyarakat ini dilakukan karena beberapa masalah seperti (1) keseharian siswa yang lebih banyak menggunakan gadget dalam mengisi waktu luang, dimana gadget ini didapatkan dengan meminjam dari orang tua mereka untuk bermain game online, (2) maraknya permainan berbasis digital selain game online seperti gamebot, playstations, sega, exbox atau yang lainnya, dan (3) terjadi kelemahan sosial yang terjadi di lingkungan rumah, diantaranya bermain HP saat di ajak berbicara, atau sibuk dengan gadgetnya padahal ada temannya di sampingnya ataupun sedang duduk bersama anggota keluarga. Pelaksanaan kegiatan ini bertempat di SD Negeri 3 Pengotan Tahun Pelajaran 2019/2020. Tahapan pelaksanaan kegiatan pengabdian ini yaitu (1) identifikasi masalah (2) analisis kebutuhan; (3) merancang pembinaan dan pendampingan; (4) melaksanakan pembimbingan; (5) monitoring dan observasi hasil kegiatan; dan (6) pelaporan dan tindaklanjut. Hasil pengabdian ini adalah (1) siswa SD Negeri 3 Pengotan sudah mengenal beberapa jenis permainan tradisional diantaranya meong-meong, congklak, curik-curik, sentil-sentilan, cingklak, meselondor, serta metembing, dan (2) tercipta keceriaan dan terjalin kerjasama yang baik antar siswa kelas IV, V dan VI.
\end{abstract}

Kata kunci: permainan tradisional; sekolah dasar.

\begin{abstract}
This community service aimed at assisting the SDN 3 Pengotan to introduce Balinese traditional games by implementing traditional games extracurricular. This community service was conducted because of several problems i.e. (1) most of students' time were used for playing online games in which they used their parents' gadget to play it, (2) there were many digital-based games other than online games such as gamebot, playstations, sega, exbox, etc, (3) there was a decrease of social activity at home, such as playing handphone when talking to others, or being busy with the gadget while having friends with or having family together. The study was conducted at SDN 3 Pengotan in academic year 2019/2020. The steps of this community service were (1) problem identification (2) needs analysis; (3) designing coaching and mentoring; (4) carry out mentoring; (5) monitoring and observing the results of activities; (6) reporting and follow-up. The results of this community service were (1) the students of SDN 3 Pengotan were familiar with some traditional games such as meong-meong, congklak, curik-curik, sentilsentilan, cingklak, meselondor, and metembing, and (2) there was a joy and good cooperation among students of class IV, V and VI.
\end{abstract}

Keywords: traditional games; elementary school.

\section{PENDAHULUAN}

Desa Pengotan sebagai desa lokasi Pengabdian pada Masyarakat (P2M) memiliki berbagai potensi yang dapat dikembangkan baik di bidang pendidikan, budaya, wisata, ekonomi dan bidang- bidang lainnya. Di Desa Pengotan terdapat lembaga pendidikan TK dan SD. Sekolah Dasar yang ada di Desa Pengotan antara lain Sekolah Dasar Negeri 1 Pengotan, Sekolah Dasar Negeri 2 Pengotan dan Sekolah Dasar Negeri 3 Pengotan

Keberadaan Sekolah Dasar di Desa Pengotan memberikan akses yang mudah untuk setiap warga di lingkungan Desa Pengotan untuk menempuh pendidikan Sekolah Dasar yang dekat. Jika dilihat dari 
keberadaan Sekolah Dasar tersebut, penulis memusatkan kegiatan ini di Sekolah Dasar Negeri 3 Pengotan, sekolah ini telah memiliki berbagai ekstrakurikuler yang sudah dijalankan sebelumnya, diantaranya kegiatan ekstrakurikuler pramuka dan ekstrakurikuler tari. Kegiatan ekstrakurikuler ini dilaksanakan terjadwal yaitu pada hari sabtu sebagai kegiatan pengembangan diri di Sekolah Dasar Negeri 3 Pengotan tersebut. Berdasarkan keberadaan ekstrakurikuler yang dimiliki oleh Sekolah Dasar tersebut, maka penulis membantu memberikan pelatihan tentang permainan tradisional. Pelatihan permainan tradisional ini dapat dijadikan program ekstrakurikuler tambahan oleh Sekolah Dasar Negeri 3 Pengotan sebagai ekstrakurikuler tambahan sebagai variasi selain ekstrakurikuler pramuka dan ekstrakurikuler tari yang dapat dipilih dan diikuti oleh siswa-siswi Sekolah Dasar Negeri 3 Pengotan. Hal ini dilakukan sebagai wujud pelestarian permainan tradisional yang dewasa ini semakin tergerus oleh permainan modern salah satunya yang sedang berkembang antara lain permainan berbasis digital selain game online seperti gamebot, playstations, sega, exbox dan lain sebagainya

Pemilihan bentuk P2M ini melihat perkembangan anak usia Sekolah Dasar pada masa ini masih senang bermain. Untuk itu perlu dikembangkan dan difasilitasi agar hasrat anak untuk bermain mendapatkan tempat sekaligus edukasi terhadap bentuk-bentuk permainan yang pernah ada sebelumnya untuk menciptakan kepuasan, kesenangan dan hiburan disela kepadatan mereka dalam belajar di sekolah.

Permainan tradisional berbasis local genius masyarakat Bali yang salah satunya diciptakan permainan megoak-goakan oleh Raja Buleleng yang bernama Ki Barak Panji Sakti pada tahun 1960 yang terinspirasi dari burung gagak yang sedang mengincar mangsanya dengan mengeluarkan taktik menarik untuk menangkap mangsanya (Dewi, 2020). Selain permainan megoak-goakan ada pula permainan tradisional meong-meongan yang berasal dari daerah Kabupaten Karangasem Bali. Di luar Bali juga ada permainan sejenis ini namun beda penyebutan nama dari permainan meong-meongan. Keberadaan permainan meong-meongan ini sudah ada berpuluh-puluh tahun yang lalu namun sampai saat ini belum mengetahui pencipta dari permainan ini. Secara pastinya permainan ini sudah ada dan masih tetap dimainkan sebagai salah satu bentuk permainan tradisional Bali yang dapat dilaksanakan pada kegiatan olahraga rekreasi untuk anak-anak usia Sekolah Dasar.

Demi menjaga dan melestarikan permainan tradisional diperlukan secara kontinyu mengajak anak-anak untuk ikut serta memainkan paling tidak salah satu dari permainan tradisional yang kita miliki sebagai wujud pelestarian agar tidak tergerus dengan perkembangan permainan modern di era digitalisasi revolusi industri 4.0. Sehingga anakanak kita teap memiliki kearifan lokal sebagai bagian dari local genius masyarakat Bali. Kearifan lokal yang dimaksud adalah budaya masyarakat setempat dan lebih menekankan pada tempat dan lokalitas yang sangat memperhatikan letak geografis suatu wilayah, yang merupakan faktor penting untuk hidup bermasyarakat dalam pengaturan bernegara yang menjunjung tinggi nilai-nilai luhur yang berlaku dalam tatanan kehidupan masyarakat sebagai wujud pelestarian (Njatrijani, 2018). Pengaturan kearifan lokal menurut UU No. 32 Tahun 2009 tentang Perlindungan dan Pengelolaan Lingkungan Hidup Pasal 1 angka 30 adalah nilai-nilai luhur yang berlaku di dalam tata kehidupan masyarakat yang bertujuan untuk melindungi sekaligus mengelola lingkungan hidup secara lestari.

Kegiatan pelatihan permainan tradisional merupakan bentuk dukungan terhadap tahap perkembangan anak baik secara fisik maupun psikis anak, sehingga anak mempunyai kebebasan untuk menyalurkan dan mengekspresikan dirinya tanpa harus merasa salah dan terbatasi oleh peraturan, kegiatan bermain penting untuk anak dalam mengembangkan aspek-aspek perkembangan anak. Aspek tersebut ialah aspek fisik, sosial emosional dan kognitif. Melalui aktifitas bermain, anak akan mendapatkan kesenangan dan juga kepuasan diri. Kegiatan yang dianggap menyenangkan bagi anak-anak akan senantiasa selalu diulang-ulang sampai merasa terpuaskan. Aktifitas bermain bagi anak yang melibatkan gerak anak seperti yang terdapat pada permainan tradisional mempunyai pengaruh positif terhadap pertumbuhan dan perkembangan anak, khususnya perkembangan jasmani anak (Erfayliana, 2016) Program pelestarian permainan tradisional anak-anak sangat penting, mengingat era revolusi industri 4.0 ini para siswa sudah diganjar dengan keberadaan game online berbasis internet dan smartphone. Berdasarkan hal tersebut dibuatlah program pengabdian pada masyarakat untuk membantu mengenalkan dan memberikan pelatihan permainan trasional kepada para siswa Sekolah Dasar Negeri 3 Pengotan. Beberapa bentuk permainan di era digitalisasi dapat 
menghilangkan rasa sosial pada setiap anak. Pelaksanaan kegiatan ini dilaksanakan pada hari Sabtu dipusatkan di Sekolah Dasar Negeri 3 Pengotan.

Banyak anak usia sekolah dasar saat ini sudah mahir dalam memainkan permainan game baik yang ada di handphone selular orang tua, kakak atau kerabatnya atau mungkin miliknya sendiri, atau dibelikan gamebot sebagai hadiah ulang tahun atau reward karena telah mendapatkan juara kelas atau telah menyelesaikan sesuatu yang diperintahkan oleh orang tuanya dengan maksimal. Tidak dapat dipungkiri bahwa setiap anak bermain game baik dari gadget ataupun gamebot banyak dari anak-anak kita yang hanya terfokus terhadap game yang mereka mainkan, dan banyak yang tidak memperdulikan orang yang berada di samping mereka.

Berdasarkan hasil penelitian ditemukan bahwa para pecandu game online menghabiskan waktu yang lebih banyak untuk bermain game online lebih dari 12 jam per hari, melihat hal ini kaitan antar game online dengan kesehatan adalah dimana seseorang yang cenderung lebih mementingkan berinteraksi dengan orang hanya didunia maya dimana pada kenyataan mereka dan menganggu sistem kerja otak. Dampak seseorang yang mengalami kecanduan terhadap video atau permainan berbasis internet (game online) sangat besar (Akbar, 2020).

Terkait uraian situasi, kondisi yang ada di Sekolah Dasar yang ada di Desa Pengotan Bangli kurang mengenal dengan permainan asli tradisional Bali, karena pada era revolusi industri 4.0 ini para siswa sudah diganjar dengan keberadaan game online berbasis internet dan smartphone. Berdasarkan hal tersebut dibuatlah program pengabdian pada masyarakat untuk membantu mengenalkan dan memberikan pelatihan permainan tradisional kepada para siswa SD Negeri 3 Pengotan.

\section{METODE}

Program Pengabdian pada Masyarakat ini dilaksaksanakan di Kabupaten Bangli bagian Utara, dengan mengambil tempat di Desa Pengotan yang terdiri dari Sekolah Dasar Negeri 1 Pengotan, Sekolah Dasar Negeri 2 Pengotan dan Sekolah Dasar Negeri 3 Pengotan. Namun yang dipilih sebagai tempat pelaksanaan program pelatihan permainan tradisional adalah di Sekolah Dasar Negeri 3 Pengotan yang dilaksanakan pada tahun ajaran 2019/2020.

Metode pelaksanaan pengabdian ini menggunakan Metode PALS yang terdiri dari (1) identifikasi masalah tentang permasalahan terkait pengetahuan siswa terhadap permainan tradisional Bali; (2) melakukan analisis kebutuhan untuk mengatasi permasalahan yang terjadi untuk dibuatkan program pelatihan permainan tradisional Bali sebagai wujud local genius pelestarian dan menjaga kearifan lokal; (3) merancang program pelatihan permainan Tradisional Bali bersama instruktur yang dapat digunakan sebagai ekstrakurikuler tambahan di Sekolah Dasar Negeri 3 Pengotan Bangli; (4) melaksanakan pendampingan pelatihan permainan tradisional sebagai variasi tambahan ekstrakurikuler yang ada di Sekolah Dasar Negeri 3 Pengotan Bangli; (5) monitoring dan observasi kegiatan; serta (6) laporan dan tindaklanjut keberhasilan program.

Metode pelaksanaan Pengabdian kepada Masyarakat ini dapat digambarkan sebagai berikut.

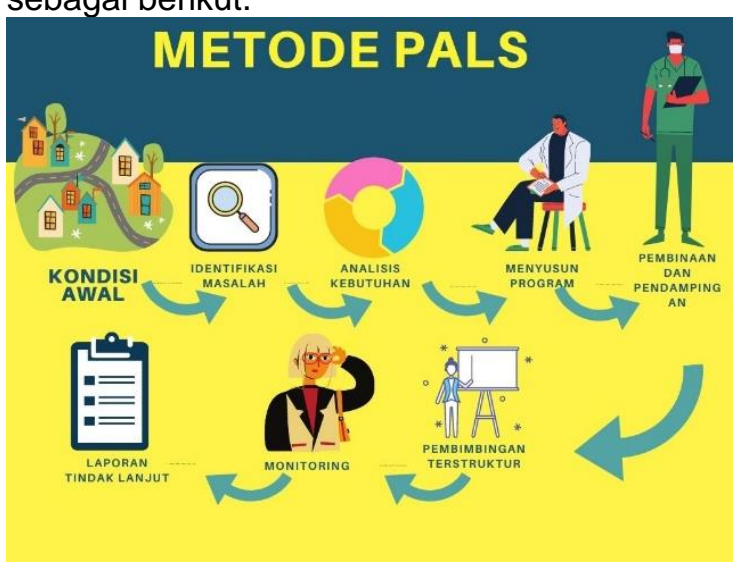

Gambar 1. Bagan Metode Pelaksanaan

Pada tahap pelaksanaan program dilakukan (1) koordinasi dan pembekalan tim kerja pelaksana program sesuai peruntukan mengatasi masalah pengabdian.

Melaksanakan penyusunan rencana program strategis sesuai dengan metode participatory action learning system (PALS). (3) Perancangan Program program pelatihan permainan Tradisional Bali bersama instruktur yang dapat digunakan sebagai ekstrakurikuler tambahan di Sekolah Dasar Negeri 3 Pengotan Bangli, (4) Pelaksanaan aktivitas-aktivitas inisiasi program pengabdian, meliputi (a) pembinaan, (b) pendampingan, (c), pembimbingan terstruktur pada siswa di Sekolah Dasar Negeri 3 Pengotan Bangli.

\section{HASIL DAN PEMBAHASAN}

Sebelum melakukan pelatihan Permainan Tradisional Wujud Pelestarian Permainan Berbasis Local Genius Di Sekolah Dasar Negeri 3 Pengotan maka dilakukan proses perencanaan dengan Tim pengabdian (yang terdiri dari Dosen dan Mahasiswa), serta instruktur yang membantu melatih para siswasiswa Sekolah Dasar Negeri 3 Pengotan dalam bermain permainan tradisional. Berdarkan 
perencanaan tersebut dipilihlah beberapa permainan tradisional yang akan disiapkan untuk dilatihkan ke siswa-siswi Sekolah Dasar Negeri 3 Pengotan.

Pada tahap perencanaan tersebut dipilihlah beberapa permainan tradisional yang akan diterapkan di Sekolah Dasar Negeri 3 Pengotan bersama Tim Pengabdian dan instruktur, diantaranya Permainan Tradisional meong-meong, congklak, curik-Curik, SentilSentilan, Cingklak, Meselondor, dan Metembing. Semua bentuk permainan tradisional tersebut dilaksanakan secara bergantian dan sudah terjadwal setiap hari Sabtu. Pemilihan hari Sabtu dilakukan karena hari tersebut merupakan space yang disediakan sekolah untuk kegiatan pengembangan diri dari seluruh siswa-siswa Sekolah Dasar Negeri 3 Pengotan.

Berdasarkan perencanaan yang telah disusun dan dilakukan tahap pelaksanaan kegiatan pengabdian ini maka dapat dipaparkan dengan hasil sebagai berikut:

Permainan Tradisional Meong-meong dilakukan dengan membentuk lingkaran, ada yang jadi meong (kucing) dan ada yang jadi bikul (tikus). Sebelum melakukan permainan ini terlebih dahulu dilakukan orientasi terkait aturan, pelafafalan dan menyanyikan lagu tradisional meong-meong berbahasa bali, dan menunjuk dengan secara undian baik dengan Hompimpa Alaium Gambreng atau dengan suit untuk menentukan anak yang berperan sebagai sati orang sebagai Meong (kucing) dan satu orang sebagai kucing.

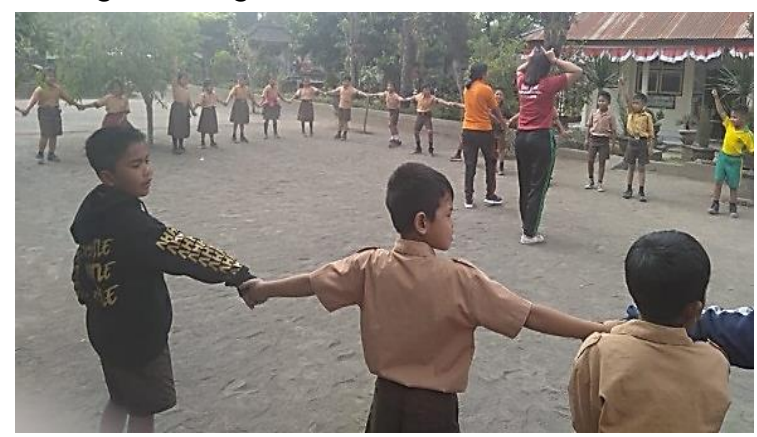

Gambar 2. Orientasi siswa pada teknis

Pelaksanaan permainan tradisional meongmeongan.

Permainan Tradisional Meong-meong dilakukan dengan diiringi lagu yang dinyanyikan oleh peserta yang ikut dalam permainan tradisional meong-meongan ini, Setelah lirik terakhir, maka akan ada sesi kejar-kejaran antara si kucing dengan si tikus. Lirik lagu tradisional meong-meong dalam Bahasa Tradisional Daerah Bali sebagai berikut.
"Meong-meong alih je bikule, Bikul gede-gede, Buin mokoh-mokoh, Kereng pesan ngerusuhin, Juk meng juk bikul"

Permainan meong-meong ini sangat menarik perhatian siswa-siswi Sekolah Dasar Negeri 3 Pengotan Bangli. Bentuk permainan ini adalah kooperatif sehingga dapat membentuk karakter setiap siswa-siswa Sekolah Dasar Negeri 3 Pengotan Bangli.

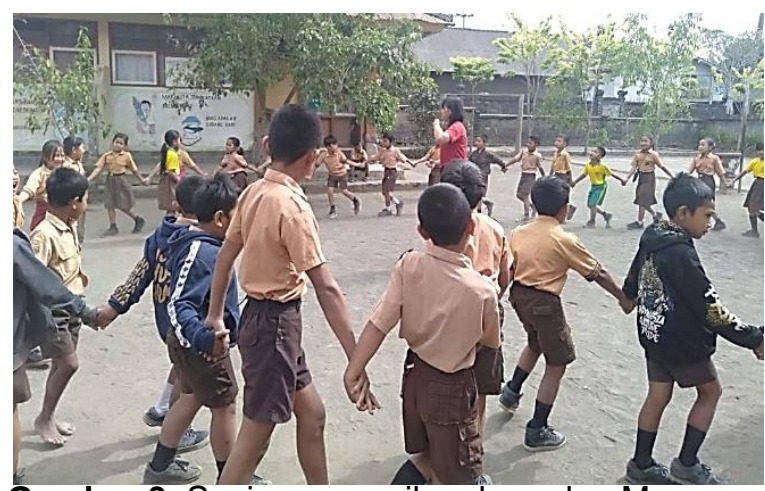

Gambar 3. Sesi menyanyikan lagu dan Meong sudah siap mengejar Bikul siswa pada teknis Pelaksanaan permainan tradisional meongmeongan.

Congklak adalah permainan yang menggunakan papan congklak dan biji congklak sebagai alat permainan, namun jika tidak ada, biasanya akan dimainkan dengan membentuk garis dan lubang di tanah serta biji congklak diganti dengan batu-batu kecil. Permainan ini dimainkan oleh 2 orang. Papan congklak memiliki 14 lubang yang saling berhadapan dan 2 lubang besar yang berhadapan disisi lain.

Berbeda dengan pelaksanaan permainan tradisional congklak yang penulis lakukan di dalam ruangan, pemilihan dalam ruangan dilakukan karena pada kesempatan tersebut terjadi cuaca yang kurang bersahabat, sehingga tidak memungkinkan dilakukan di luar ruangan, maka untuk mengganti lubang-lubang sebagai ciri khas papan congklak penulis gunakan garis lantai keramik dengan jumlah lubang yang sama dengan garis keramik yang diperlukan. Melihat keterbatasan sarana dan prasarana serta cuaca yang tidak mendukung permainan tradisional congklak maka dicarikan alternatif baik dari sarana dan prasarana namun tidak menurunkan semangat dan minat siswa siswi bermain permainan tradisional congklak di Sekolah Dasar Negeri 3 Pengotan. 


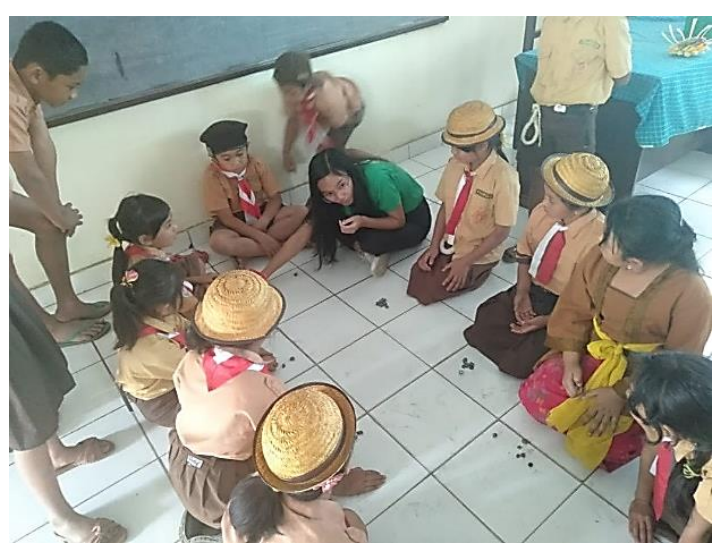

Gambar 3. Pelaksanaan pelatihan permainan tradisional congklak.

Selanjutnya, curik-curik merupakan Permainan yang hampir mirib dengan ular naga, 2 orang di depan sebagai ketua regu dan memiliki nama samaran. Teman-temannya yg lain akan memilih regu masing-masing tanpa sepengetahuan mereka. Setelah selesai regu akan melakukan tarik menarik sampai salah satu regu habis. Lirik lagu curik-curik dalam Bahasa Tradisional Daerah Bali sebagai berikut.

"Curik-curik semental, Alang-alang, boko-boko, Tiang meli pohe, Aji satak, aji satus keteng, Mara bakat, anak bagus peceng, Enjok-enjok."

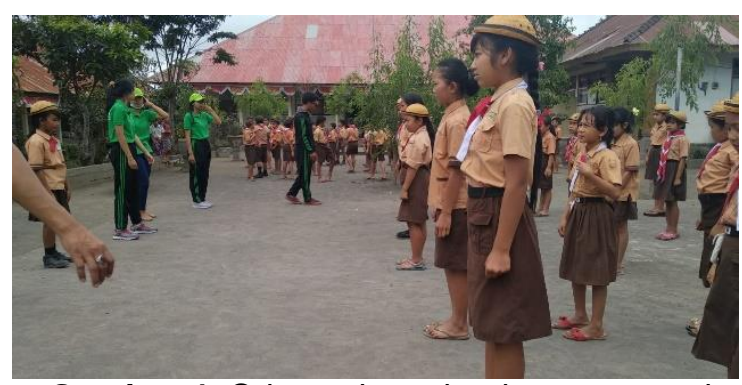

Gambar 4. Orientasi pembagian regu untuk permainan Tradisional Curik-Curik.

Sentil-sentilan adalah permainan yang digemari oleh anak laki-laki. Akan dibuat garis start terlebih dahulu, lalu sekitar 2-3m akan dibuat lubang, dan peserta bertugas untuk memasukkan kelereng ke dalam lubang dengan cara disentil.

Cingklak adalah permainan yang menggunakan guli dan 6 batu. Pertamapertama guli akan dilayangkan ke atas dan mengambil batu satu persatu sampai keenamnya dan yang terakhir adalah mencari nilai dengan cara batu dilayangkan dan ditangkap.

Metembing juga permainan tradisional yang dimainkan dengan uang logam. Uang logam dilempar oleh masing-masing peserta, yang terdekat dengan lubang, dialah yang mendapatkan giliran pertama. Semua uang logam dilempar dan yang masuk lubang akan menjadi hak pemain.

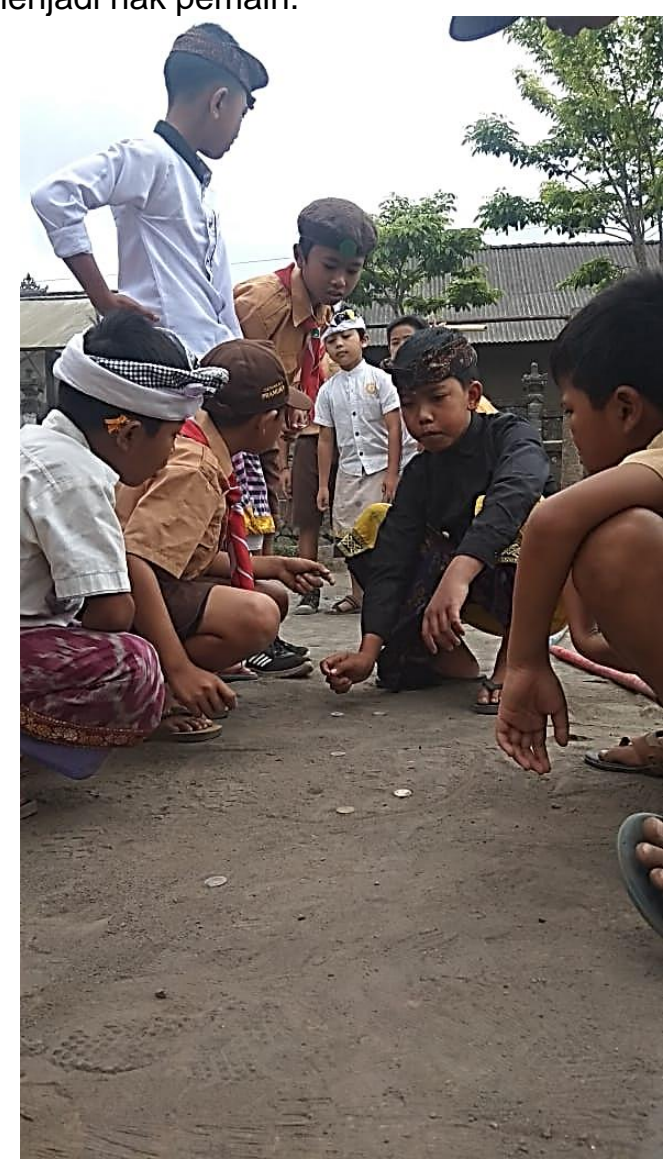

Gambar 5. Pelaksanaan permainan tradisional matembing terlihat juga anak-anak sedang bermain permainan tradisional matembing dengan pakaian Adat Bali yang terdiri dari Udeng, Baju/Safari, Saput, dan Kamen.

Permainan tradisional yang terakhir kami lakukan di Sekolah Dasar Negeri 3 Pengotan adalah permainan Tradisional Meselondor. Permainan Tradisional ini menggunakan batang pohon pisang sebagai alat untuk berperang dengan lawan.

Setelah semua kegiatan pelatihan permainan tradisional ini penulis laksanakan ada beberapa hal yang terjadi selama proses pelaksanaannya. Selain keberhasilan yang telah dicapai, ada beberapa kendala yang dialami oleh penulis (dosen dan mahasiswa) dan instruktur dalam melaksanakan program pelatihan bagi siswa Sekolah Dasar Negeri 3 Pengotan. Adapun hambatan-hambatan yang kami hadapi ketika pelaksanaan program pelatihan ini di adalah sebagai berikut.

Hambatan pertama yaitu pengetahuan beberapa siswa terhadap permainan tradisional masih kurang sehingga perlu pikiran dan tenaga ekstra dalam pengenalan kegiatan yang akan dilaksanakan. Hambatan yang kedua yaitu situasi siswa selama pelatihan sangat 
ribut, sehingga pada saat memberikan pengarahan sedikit mengalami hambatan.

Hambatan non teknis yang dihadapi saat melaksanakan kegiatan ini yaitu waktu pelaksanaan terkadang tidak sesuai dengan yang telah dijadwalkan mengingat adanya beberapa kegiatan yang dilaksanakan di sekolah namun itu tidak terlalu berarti dan factor cuaca namun tidak terlalu berarti.

Kehadiran Penulis di Sekolah Dasar Negeri 3 Pengotan memberikan manfaat yang sangat terasa bagi keberadaan sekola karena program ini berhasil membuat anak-anak sudah mampu mengenal beberapa warisan tradisi permainan tradisional Bali yang saat ini semakin tergerus dangan permainan yang sangat modern dan canggih.

Selama pelaksanaan Permainan tradisional sangat bermanfaat dalam peningkatan motorik siswa, kognitif siswa, afektif siswa, sosial siswa dan seni suara diantaranya sebagai berikut.

Pertama, Permainan tradisional dapat meningkatkan kemampuan motorik, kemampuan motorik pada anak ada beberapa bentuk, antara lain motorik kasar dan halus. motorik kasar adalah perkembangan kemampuan anak anak yang melibatkan otototot besar dalam melakukan gerakan dan sikap tubuh (Ananditha, 2017). Kemampuan motorik kasar terbentuk misalnya pada saat permainan tradisional meong-meong, curik-curik yang mengedepankan kecakapan dan ketangkasan yang melibatkan otot dalam tubuh. Motorik halus adalah kemampuan kemampuan dalam menggunakan jari untuk menggunakan berbagai kegiatan, seperti melakukan gerakan (motion), menempel, mencubit, memotong, melukis, dan lain-lain. Pada kegiatan permainan tradisional pembentukan motirik halus terjadi pada permainan salah satunya permainan tradisional congklak, permainan tradisional matembing yang lebih menekankan motorik halus dalam bermain.

Kedua, permainan tradisional dapat meningkakan kemampuan sosial siswa, kemampuan sosial siswa terbentuk akibat saling terjadi hubungan sosial saling berinteraksi dan bekerjasama selama permainan tradisional berlangsung. Setiap regu dalam melaksanakan permainan tradisional ini membuat mereka harus selalu berdiskusi baik tentang tindakan yang akan mereka lakukan untuk dapat memenangkan permainan atau saling membantu untuk dapat menyukseskan dan memenangkan kompetisi dari Permainan tradisional ini.

Ketiga, permainan tradisional dapat melatih kemampuan siswa untuk belajar seni suara. Secara tidak langsung ada beberapa permainan yang diwajibkan untuk bernyanyi karena permainan tersebut memang harus diiringi oleh lagu-lagu khas daerah Bali, sesuai dengan konsep dan bentuk perminannya, seperti misalnya, Curik-Curik dan MeongMeong.

Selain ketiga temuan di atas ada kemampuan kognitif yang dapat diperoleh pada kegiatan permainan tradisional salah satunya Problem Solving. Problem Solving yang dimaksud dalam hal ini adalah kegiatan pembelajaran mandiri yang terjadi dalam diri masing-masing siswa dilatih memiliki kemampuan merumuskan permasalahan yang kompleks dan membuat sejumlah solusi untuk kemudian merefleksikan solusi tersebut dari berbagai sudut pandang (Walid et al., 2019). Kemampuan kognitif yang dapat diperoleh dalam kegiatan pelaksanan permainan tradisional antara lain Remembering, Understanding, Applying, Analyzing, Evaluating secara sederhana.

Remembering terjadi situasi siswa untuk menghafal, mengulang serangkaian kegiatan atau lagu yang telah disampikan. Understanding terjadi terjadi proses menemukan, mengenali, membedakan atau yang lainnya. Applying terjadi proses menerapkan permainan tradisional itu setelah instruksi dilakukan, atau berhitung, menunjukkan atau lainnya sesuai dengan tahap Applying. Analyzing terjadi situasi siswa memahami untuk membedakan, menyakan, menemukan dan lainnya. Evaluating permainan tradisional memberikan kemampuan menilai antar teman baik dari kemampuan, pemahaman atau lainnya, menciptakan self assemment.

\section{SIMPULAN DAN SARAN}

Adapun kesimpulan dari pelaksanaan program pelatihan permainan tradisional di SD Negeri 3 Pengotan adalah program ini berhasil membuat anak-anak sudah mampu mengenal beberapa warisan tradisi permainan tradisional Bali. Hambatan yang dialami saat pelaksanaan program dapat diatasi dengan baik karena adanya kerjasama yang baik antar dosen pelaksana, mahasiswa, dan pihak Sekolah Dasar Negeri 3 Pengotan. Perlu adanya program lanjutan supaya kemampuan yang sudah dikuasai oleh anak didik tidak cepat hilang atau dilupakan oleh mereka.

Adapun saran yang dapat kita sampaikan terkait pelaksanaan program ini adalah untuk Sekolah Dasar Negeri 3 Pengotan senantiasa melanjutkan program ini supaya sebagai wujud pelestarian budaya adiluhung Bali yang semakin ditinggalkan dan bagi penulis lain nantinya agar program ini lebih 
dikembangkan untuk mejaga warisan budaya daerah yang memiliki kearifan lokal.

\section{DAFTAR RUJUKAN}

Akbar, H. (2020). Penyuluhan Dampak Perilaku Kecanduan Game Online Terhadap Kesehatan Remaja di SMA Negeri 1 Kotamobagu. Community Engagement \& Emergence Journal, 1, 42-47. https://webcache.googleusercontent.com/ search?q=cache:UwSe7Bcall0J:https://jo urnal.yrpipku.com/index.php/ceej/article/d ownload $/ 108 / 71+\& c d=4 \& \mathrm{hl}=\mathrm{id} \& \mathrm{ct}=\mathrm{clnk} \& \mathrm{~g}$ I=id

Ananditha, A. C. (2017). Faktor-Faktor Yang Berhubungan Dengan Perkembangan Motorik Kasar Pada Anak Toddler. Jurnal Keperawatan Muhammadiyah, 2(1). https://doi.org/10.30651/jkm.v2i1.924

Dewi, N. P. C. P. (2020). No Title. JayaPangus Press, 2, 30-37. https://jayapanguspress.penerbit.org/inde x.php/ganaya/issue/view/29

Erfayliana, Y. (2016). Aktivitas Bermain dan Perkembangan Jasmani Anak. Terampil Jurnal Pendidikan Dan Pembelajaran Dasar.

Njatrijani, R. (2018). Kearifan Lokal Dalam Perspektif Budaya Kota Semarang. Gema Keadilan Edisi Jurnal 17.

Walid, A., Putra, E. P., \& Asiyah, A. (2019). Pembelajaran Biologi Menggunakan Problem Solving Disertai Diagram Tree Untuk Memberdayakan Kemampuan Berpikir Logis Dan Kemampuan Menafsirkan Siswa. IJIS Edu: Indonesian Journal of Integrated Science Education. https://doi.org/10.29300/ijisedu.v1i1.1398 